\title{
Sexual health assessment and counseling: oncology nurses' perceptions, practices, and perceived barriers
}

\author{
Jill L Depke, NP, and Adedayo A Onitilo, MD, MSCR, PhD
}

${ }^{a}$ Medical College of Wisconsin, Cancer Care Center, Milwaukee, Wisconsin; and ${ }^{b}$ Department of Oncology/Hematology, Marshfield Clinic Weston Center, Weston, Wisconsin

Background Cancer-related sexual dysfunction has a negative impact on patient quality of life.

Objective To describe oncology nurses' perceptions, practices, and perceived barriers regarding sexual health assessment and counseling.

Methods In 2005, a 31 -item questionnaire was mailed to 56 oncology nurses employed at 6 regional cancer care centers in northern, central, and western Wisconsin. Questions captured demographic information about the nurses and information about attitudes, perceptions, and practice patterns regarding patient sexual health counseling, and the barriers to discussing sexuality with patients.

Results Nearly $70 \%$ of mailed surveys were returned completed. Most of the respondents believed that sexual health concerns were important and that it was appropriate for nurses to discuss patient sexual concerns, but less than one-third of the nurses said they had offered to discuss sexual concerns with patients in the previous 12 months. Few respondents reported feeling adequately knowledgeable about talking to patients about concerns about sexual health, and more than $90 \%$ thought that additional training in sexual health counseling would increase their confidence in addressing sexual health issues.

Limitations Study findings are limited by validity of the survey instrument and issues related to self-report. Sensitivity of the topic may have resulted in selection bias.

Conclusions Sexual health among patients with cancer was recognized as important, but was discussed infrequently. Additional training may improve the ability of oncology nurses to provide sexual health counseling to patients.

S exuality is a significant contributor to patient quality of life and may be influenced by serious medical illnesses. ${ }^{1,2}$ Cancer-related sexual changes linked to diagnosis, disease, and treatment manifest most often as loss of desire and pleasure., Sexual health counseling can improve the quality of life for a person with cancer by increasing confidence and hopefulness, identifying appropriate resources, addressing body image and self-esteem issues, and exploring the emotional impact of cancer and its treatment on the patient. ${ }^{5}$ To effectively initiate conversations and ask questions about sexual concerns, health care providers must have selfawareness, the skills to do so, and comprehensive knowledge regarding sexual health. ${ }^{5}$ Nurses are well positioned to discuss these issues about sexuality with patients because of their frequent contact and established relationships with patients, so we sought to better understand nurses' attitudes toward and perceptions of sexual health counseling, the barriers to discussing the topic with patients, and the patterns of clinical practice and nature of patient inter- action in relation to sexual health counseling.

\section{Methods}

In March 2005, a 31-item questionnaire was mailed to 56 oncology nurses who were employed at 6 regional Marshfield Clinic cancer care centers in northern, central, and western Wisconsin. The mailing included an associated cover letter and consent form. The questions were designed to capture demographic information about the nurses, as well as information about their attitudes, perceptions, practice patterns regarding patient sexual health counseling, and the barriers to discussing sexuality with patients. Face validity of the instrument was established through pilot testing by 4 offsite oncology nurses. All of the questionnaires that were returned with signed consent forms were included in analyses. Descriptive statistics, including mean, standard deviation, and percentages, are reported. Summation scores were generated for responses to the questions about attitude/perception, practice, and barriers, and Pearson's correlation was calculated. Analyses were 
conducted using Stata 8.0 (Stata Corporation, College Station, TX, USA). $P$ values of $<.05$ were considered significant. This study was approved by institutional review boards at the University of Wisconsin-Eau Claire and the Marshfield Clinic Research Foundation.

\section{Results}

In all, 39 of the 56 oncology nurses (69.6\%) returned completed surveys (Table 1). The respondents' attitudes/perceptions toward sexual health counseling are summarized in Table 2. All of the respondents considered addressing the sexual needs of patients to be an important component in the care of cancer patients, but most (69\%) indicated that physicians had the primary responsibility for discussing sexual concerns with patients in their respective practices. Although 100\% of respondents believed it was appropriate for nurses to discuss sexual concerns if the patient initiated the discussion, only $61 \%$ thought it proper for nurses to initiate the discussion. Most of the respondents reported feeling comfortable discussing patients' sexual needs with patients, but strongly agreed that additional training would increase comfort level. Despite these findings and a willingness among the respondents to more actively engage advising patients on sexuality, more than two-thirds of nurses had not offered to discuss sexual concerns with patients in the previous 12 months.

Barriers to discussing sexual concerns included lack of expertise or training on the part of the nurse, patient embarrassment, privacy issues, and time constraints. In practice, only $27 \%$ of respondents reported feeling knowledgeable about sexuality, and $92 \%$ indicated that additional training in sexual health counseling would increase their confidence in addressing sexual health issues. Similarly, although two-thirds of nurses reported that they would encourage patients to discuss their sexual problems, only $16 \%$ and $19 \%$ of respondents reported respective patientand nurse-initiated discussions about sexual needs/issues in the previous year. Strong correlation was noted between attitude/perception and practice scores (Pearson correlation coefficient, $0.5484, P=.0006$ ).

\section{Discussion}

Patient sexuality is altered in an estimated $40 \%-100 \%$ of oncology patients with effects on body image, relationships, identity, self-esteem, and sexual functioning., ${ }^{6,7}$ Here, we report oncology nurses' perceptions of sexual health counseling in a large, regional, rural clinic system in Wisconsin. Participating nurses considered addressing sexual needs to be an important component in the care of cancer patients and there was a strong correlation between scores for sexual health attitudes/perceptions and practices. However, more than $90 \%$ of nurses indicated that physicians had primary responsibility for discussing sexual concerns with patients,

\begin{tabular}{|c|c|}
\hline Characteristic & $\begin{array}{c}\text { No. of } \\
\text { respondents (\%) }\end{array}$ \\
\hline \multicolumn{2}{|l|}{ Gender } \\
\hline $\begin{array}{l}\text { Female } \\
\text { Male }\end{array}$ & $\begin{aligned} 38 & (97.4) \\
1 & (2.6)\end{aligned}$ \\
\hline \multicolumn{2}{|l|}{ Age, y (mean, 36 y) } \\
\hline $\begin{array}{l}21-35 \\
36-55 \\
>55\end{array}$ & $\begin{array}{c}8(20.5) \\
27(69.2) \\
4(10.3)\end{array}$ \\
\hline \multicolumn{2}{|l|}{ Ethnicity } \\
\hline $\begin{array}{l}\text { White/non-Hispanic } \\
\text { Other (unavailable) } \\
\text { No response }\end{array}$ & $\begin{array}{c}34(87.2) \\
1(2.6) \\
4(10.2)\end{array}$ \\
\hline \multicolumn{2}{|l|}{ Nursing education } \\
\hline $\begin{array}{l}\text { ADN } \\
\text { Diploma } \\
\text { BSN } \\
\text { MSN }\end{array}$ & $\begin{array}{c}13(33.3) \\
7(18.0) \\
17(43.6) \\
2(5.1)\end{array}$ \\
\hline \multicolumn{2}{|l|}{ Nurse years } \\
\hline $\begin{array}{l}\text { General } \\
0-5 \\
6-15 \\
>15 \\
\text { Oncology } \\
0-5 \\
6-15 \\
>15\end{array}$ & $\begin{array}{c}2(5.1) \\
18(46.2) \\
19(48.7) \\
19(48.7) \\
9(23.1) \\
11(28.2)\end{array}$ \\
\hline \multicolumn{2}{|l|}{ Religious affiliation } \\
\hline $\begin{array}{l}\text { Catholic } \\
\text { Lutheran } \\
\text { Other } \\
\text { No response }\end{array}$ & $\begin{array}{l}11(28.2) \\
15(38.5) \\
9(23.1) \\
4(10.2)\end{array}$ \\
\hline \multicolumn{2}{|c|}{ Annual household income, $\$$} \\
\hline $\begin{array}{l}20,000-39,900 \\
40,000-59,900 \\
60,000-79,900 \\
80,000-99,900 \\
>100,000\end{array}$ & $\begin{array}{l}2(5.1) \\
7(17.9) \\
14(36.0) \\
7(18.0) \\
9(23.0)\end{array}$ \\
\hline
\end{tabular}

ADN, Associate's Degree in Nursing; BSN, Bachelor of Science in Nursing; MSN, Master of Science in Nursing

and few considered themselves knowledgeable about sexuality counseling. Most nurses felt that more training in sexual health would increase their comfort assisting patients with issues related to sexuality. These findings suggest that a conflict continues to exist between nurse beliefs and practice patterns regarding sexual health counseling.

By legitimizing the topic of sexuality as an essential component of treatment early on, health care providers support patients' abilities to raise concerns about sexuality as they arise during illness and recovery. ${ }^{8}$ Evidence sug- 
TABLE 2 Selected attitudes and perceptions among respondent oncology nurses regarding sexual health counseling

\begin{tabular}{|c|c|c|c|}
\hline Attitude or perception & Mean (SD) & $\begin{array}{l}\text { Usually or } \\
\text { always }\end{array}$ & Scale \\
\hline Do you think that it is appropriate for nurses to discuss sexual concerns with patients? & $4.26(.75)$ & 82.05 & $1-5^{a}$ \\
\hline $\begin{array}{l}\text { Do you think that it is appropriate for nurses to discuss sexual concerns with patients if the } \\
\text { patient initiates the discussion? }\end{array}$ & $4.74(.44)$ & 100 & $1-5^{a}$ \\
\hline $\begin{array}{l}\text { Do you think it is appropriate for nurses to initiate discussion of sexual concerns with } \\
\text { patients? }\end{array}$ & $3.74(.68)$ & 61.54 & $1-5^{a}$ \\
\hline Do you feel comfortable discussing sexual concerns with patients? & $3.85(.93)$ & 69.23 & $1-5^{a}$ \\
\hline $\begin{array}{l}\text { Do you feel it is the responsibility of the physician to initiate and discuss sexual concerns } \\
\text { with the patient? }\end{array}$ & $4.00(1.0)$ & 69.23 & $1-5^{a}$ \\
\hline $\begin{array}{l}\text { How comfortable do you feel in engaging in a discussion with patients about their sexual } \\
\text { issues? }\end{array}$ & $2.81(.78)$ & 69.45 & $1-4^{b}$ \\
\hline Would training in this subject make you more comfortable? & $3.47(.65)$ & 91.67 & $1-4^{c}$ \\
\hline Should addressing the sexual needs of patients be part of the care of cancer patients? & $3.46(.51)$ & 100 & $1-4^{\mathrm{d}}$ \\
\hline Do you think you need training about sexuality and sexual issues of cancer patients? & $3.05(.89)$ & 74.36 & $1-4^{e}$ \\
\hline How much training/education have you had about sexuality and sexual issues? & $2.21(.70)$ & 35.9 & $1-4^{e}$ \\
\hline $\begin{array}{l}\text { How prepared would you be to consider taking an active part in advising patients in this } \\
\text { area of their care? }\end{array}$ & $2.86(.67)$ & 75.67 & $1-4^{c}$ \\
\hline To what extent do you feel knowledgeable about sexuality? & $3.10(.74)$ & 27.02 & $1-5^{f}$ \\
\hline
\end{tabular}

gests that oncology nurses are more likely than medical or surgical nurses to recognize the value of discussing sexuality, and the immediate and ongoing relationship between patient and oncology nurse during cancer treatment presents numerous opportunities to dialogue with patients regarding sexual health issues. ${ }^{9}, 10$ However, as the findings in this study and others suggest, sexual health issues are often not raised and there are several barriers to frank discussion, including lack of knowledge and expertise on the part of the nurse, myths surrounding sexuality and cancer, and topic-related discomfort or embarrassment. . $^{8,9,11-15}$ It is important for nurses to overcome these barriers and cultivate the skills necessary to broach the subject of sexual health in an appropriate and sensitive manner so that oncology patients are able to navigate and inquire about sexual health during treatment and recovery. ${ }^{15}$

Research findings indicate that patients prefer that discussions about sexual health be initiated by health care professionals, yet the percentage of nurses reporting discussion of these concerns with patients in this and other studies is small. ${ }^{716-18}$ Findings of a strong correlation between attitude/perception and practice patterns suggest that the ability of oncology nurses to initiate sexual health discussions would benefit from their receiving additional training and skill building. We recommend development and implementation of a nursing-specific "Sexual Health Education
Intervention Experience" as continuing medical education for oncology nurses. Content areas might encompass basics of sexuality, sexual dysfunction and the cancer patient, obtaining a sexual history, strategies to guide discussions on sexual health, and basic counseling techniques with the goal of improving incorporation of sexual health assessment and counseling into routine patient care with referral for more intensive therapy as necessary.

Study findings are limited by validity of the survey instrument used and issues related to self-report, including inaccurate recall and questionable comprehension or interpretation. Sensitivity of the topic may have resulted in selection bias, but use of a mailed survey to ensure anonymity may have mitigated this concern. Ultimately, the high response rate and agreement of findings with existing literature suggests generalizability amongst oncology nursing communities.

If oncology nurses are to provide a holistic approach to patient care, they must first understand the biological, psychological, and social aspects of sexual concerns raised by their patients. ${ }^{19}$ Enhanced understanding of the attitudes and knowledge of nurses toward sexual health counseling is fundamental to identifying and addressing barriers to this important aspect of cancer care. The burden of responsibility to raise sexual issues continues to rest on patients, ${ }^{20}$ but survey responses suggest a willingness to bolster sexual 
health programming and an opportunity to improve practices via additional training.

\section{Acknowledgment}

The authors thank the Marshfield Clinic Research Foundation's Office of Scientific Writing and Publication for assistance in preparing this manuscript.

\section{References}

1. Robinson J, Molzahn A. Sexuality and quality of life. J Gerontol Nurs. 2007;33:19-27.

2. World Health Organization. Sexual health: a new focus for WHO. Progress in Reproductive Health Research, 67. Geneva, Switzerland: 2004.

3. Schover LR. Sexuality and Fertility after Cancer. 2005. http:// asheducationbook.hematologylibrary.org/content/2005/1/523.full. pdf + html. Released January 1, 2005. Accessed 12 March, 2013.

4. Stuyck K. Sex after cancer treatment: many cancer-related sexual problems can be solved. OncoLog 2012;57.http://www2.mdanderson.org/depts/oncolog/articles/12/1-jan/1-12-hc.html. Released January 2012. Accessed 12 March, 2013.

5. Crumlish B. Sexual counseling by cardiac nurses for patient following and MI. Br J Nurs. 2004;13:710-713.

6. Schover LR. Counseling cancer patients about changes in sexual function. Oncology (Williston Park). 1999;13:1585-1591.

7. Gott M, Galena E, Hinchliff S, Elford H. 'Opening a can of worms': GP and practice nurse barriers to talking about sexual health in primary care. Fam Pract. 2004;21:528-536.

8 .Katz A. The sounds of silence: sexuality information for cancer patients. J Clin Oncol. 2005;23:238-241.
9. Magnan M, Reynolds K. Barriers to addressing patient sexuality concerns across five areas of specialization. Clin Nurse Spec. 2006;20:285-292.

10. Warner P, Rowe T, Whipple B. Shedding light on the sexual history. Am J Nurs. 1999;99:34-41.

11. Matocha LK, Waterhouse JK. Current nursing practice related to sexuality. Res Nurs Health. 1993;16:371-378.

12. Haboubi NH, Lincoln N. Views of health professionals on discussing sexual issues with patients. Disabil Rehabil. 2004;25:291-296.

13. Quinn B. Sexual health in cancer care. Nurs Times. 2003;99:32-34.

14. Reynolds K, Magnan M. Nursing attitudes and beliefs toward human sexuality: collaborative research promoting evidence-based practice. Clin Nurse Spec. 2005;19:255-259.

15. Julien JO, Thom B, Kline NE. Identification of barriers to sexual health assessment in oncology nursing practice. Oncol Nurs Forum. 2010;37:186-190.

16. Lewis S, Bor R. Nurses knowledge of and attitudes toward sexuality and the relationship of these with nursing practice. J Adv Nurs. 1994;20:251-259.

17. Rice A. Sexuality in cancer and palliative care 1 : effects of disease and treatment. Int J Palliat Nurs. 2000;6:392-397.

18. Dattilo J, Brewer MK. Assessing client's sexual health as a component of holistic nursing practice: senior nursing students share their experiences. J Holistic Nurs. 2005;23:208-219; discussion 220-223.

19. Kotronoulas G, Papadopoulou C, Patiraki E. Nurses' knowledge, attitudes, and practices regarding provision of sexual health care in patients with cancer. Support Care Cancer. 2009;17:479-501.

20. Butler L, Banfield V. Oncology nurses' views on the provision of sexual health in cancer care. J Sex Reprod Med. 2001;1:35-39. 